\title{
REFLEXIONES \\ FILOSÓFICAS SOBRE LA TECNOLOGÍA Y SUS NUEVOS ESCENARIOS
}

Floralba Aguilar Gordón ${ }^{*}$

\section{Resumen}

El artículo "Reflexiones filosóficas sobre la tecnología y sus nuevos escenarios", inicia con una aproximación conceptual a la tecnología, en la que presenta una breve descripción de algunas características históricas, reflexiona acerca de la función y del uso de la tecnología en los nuevos escenarios de la sociedad.

Avanza con el análisis de los fundamentos de la tecnología en cuanto tal, aborda los fundamentos filosóficos y sobre los fundamentos sociológicos de la tecnología aplicada a la educación.

Continúa con la reflexión acerca de los problemas y de los saberes de la tecnología; en este sentido, re-piensa a la tecnología como realidad y como conocimiento; estudia la naturaleza de la realidad y del conocimiento tecnológico; revisa por qué el ser humano, la educación y la tecnología

* Doctora en Filosofía. Magíster en Educación Superior. Magíster en Tecnología aplicada a la Educación. Docente Universidad Politécnica Salesiana. 
constituyen un problema en sí y por sí mismo; describe los saberes integradores de la tecnología con énfasis en la teoría, en la filosofía, en la axiología, y en la metodología de la tecnología.

El artículo concluye con el análisis del impacto de la tecnología en sus diversas manifestaciones: en la visión del mundo, en la educación, etcétera.

Palabras clave: tecnología, nuevos escenarios, globalización, problemas de la tecnología, saberes de la tecnología, fundamento, realidad tecnológica, conocimiento tecnológico, tecnología aplicada a la educación, impacto, implicaciones.

\section{Abstract:}

The article "Philosophical reflections on the technology and his new scenes", it initiates with a conceptual approximation of the technology, in the one that presents a brief description of some historical characteristics, he thinks it brings over of the use and of the function of the technology in the new scenes of the company. It advances with the analysis of the foundations of the technology for which checks the foundation of the technological fact in strict sense; he thinks about the philosophical foundations and about the sociological foundations of the technology applied to the education.

It continues with the reflection brings over of the problems and of the saberes of the technology; in this respect, he rethinks to the technology as reality and as knowledge; he studies the nature of the reality and of the technological knowledge; it checks why the human being, the education and the technology constitute a problem in yes and for yes same; it describes the of integration saberes of the technology emphatically in the theory of the technology, in the philosophy of the 
technology, in the axiology of the technology and in the methodology of the technology.

The article concludes with the analysis of the impact of the technology in his diverse manifestations; he thinks brings over of the incident of the technology in the vision of the world; he presents some reflections brings over of the implications of the technology applied to the education and promotes a diversity of approaches of usefulness for the educational current context.

Key words: technology, new scenes, globalization, problems of the technology, saberes of the technology, foundation, technological reality, technological knowledge, technology applied to the education, impact, implications.

\section{Introducción}

Los nuevos paradigmas generados por el avance de la ciencia y de la tecnología de los últimos tiempos contribuyen para el cambio de las percepciones sobre nosotros mismos, sobre la forma como interactuamos y sobre la manera de relacionarnos con la naturaleza.

En este panorama, surge el artículo "Reflexiones filosóficas sobre la tecnología y sus nuevos escenarios". El trabajo tiene como finalidad identificar los diversos elementos y problemas constitutivos de la realidad tecnológica como referentes para re-pensar e interpretar el contexto de la actualidad y las diferentes implicaciones de la tecnología en el accionar humano y en la construcción social.

Re-pensar la tecnología conlleva la gestación de una diversidad de enigmas cognoscitivos, como: ¿Cuál es el sentido y significado de la tecnología? ¿Cómo entender a la tecnología y a sus productos? ¿Cuáles son los nuevos escenarios de la tecnología en la actualidad? ¿Cuál es la función y el uso de la tecnología en los nuevos escenarios 
mundiales? ¿Cuáles son los problemas de la tecnología? ¿Cuáles son los saberes que aportan para la comprensión de la tecnología? ¿Cuál es la relación actual entre tecnología y educación? ¿Cuál es el impacto de la tecnología en el contexto actual?

Para responder a algunas de las inquietudes se ha sistematizado la reflexión en cuatro temáticas centrales:

En la primera se presenta una aproximación conceptual de la tecnología; se describe algunas características históricas de la tecnología; se analiza y se reflexiona acerca de la función y del uso de la tecnología en los nuevos escenarios de la sociedad.

En la segunda temática, se analiza los fundamentos de la tecnología para lo cual se revisa el cimiento del hecho tecnológico propiamente dicho, se reflexiona acerca de los fundamentos de la tecnología aplicada a la educación.

En la tercera temática se abordan los problemas y los saberes de la tecnología; en este sentido, se re-piensa a la tecnología como realidad y como conocimiento; se revisa por qué el ser humano, la educación y la tecnología constituyen un problema en sí y por sí mismo; se describe los saberes integradores de la tecnología con énfasis en la teoría, en la filosofía, en la axiología y en la metodología de la tecnología.

En la cuarta temática, se analiza el impacto de la tecnología en sus diversas manifestaciones sociales; se reflexiona acerca de la incidencia de la tecnología en la visión del mundo para lo cual se toma como punto de referencia a las revoluciones sociocultural, económica y tecnológica; se presenta algunas reflexiones sobre las implicaciones de la tecnología aplicada a la educación. 


\section{Aproximación conceptual a la tecnología}

\section{Conceptualización y breve caracterización histórica de la tecnología}

La tecnología ha sido entendida de diferentes maneras, unos la conciben como el conjunto de saberes, de habilidades, de destrezas y de medios necesarios para llegar a un fin predeterminado; otros la entienden como un conjunto de conocimientos técnicos, ordenados científicamente, que permiten diseñar y crear bienes y servicios que facilitan la adaptación al medio ambiente y la satisfacción de necesidades y deseos humanos.

Frecuentemente se da un uso indiscriminado de los términos técnica y tecnología, sin embargo, pueden establecerse diferencias, así: la técnica podría ser entendida como un procedimiento para modificar la realidad, basado en la información proporcionada por las ciencias; en cambio, la tecnología podría entenderse como el conjunto de conocimientos acerca del procedimiento técnico o éxito de la acción sobre la realidad (cfr. Fullat, 2000: 164).

Cabe explicar que el concepto de técnica quedó precisado por los griegos, de manera especial por Aristóteles, para quien la "téchne (industria, arte, capacidad) es artificiosa y no una actividad natural. La técnica es "saber (como) hacer cosas" según un eidos-idea- que el techenites (industrioso, artesano, artista) posee y que "re-produce" en la realidad (cfr. ibíd.); así lo que era idea de plato en la mente del artesano se convierte en un plato real, apto para servir un alimento mediante la poíesis o acto de producir o fabricar ${ }^{-1}$ Este recurrir momentáneo a la cultura griega tiene por fin esclarecer el actual concepto de técnica y pretende desmitologizar el vocabulario presente. A través de la historia encontramos que la tecnología surge de la inteligencia 
del ser humano para responder a sus necesidades esenciales e inmediatas.

Independientemente de las variantes de detalle según el objeto, el principio de funcionamiento y de los materiales e instrumentos utilizados en la elaboración de un invento, el punto de partida radica en la identificación del problema, la determinación de requisitos para responder a la necesidad, la formulación del principio de funcionamiento, la idea que será operativizada, el diseño que precede a la construcción, simulación o construcción de un prototipo, fase de prueba, validación y elaboración de la teoría general.

Lo importante en la caracterización histórica de la tecnología, no es destacar los inventos realizados desde el inicio de las primeras civilizaciones, desde la época prehistórica hasta los inventos recientes e innovadores sino el analizar lo que fundamenta la existencia de ellos y sus repercusiones en nuestras vidas.

Sin embargo, cabe mencionar brevemente que los hitos sobresalientes del proceso tecnológico de la humanidad como la invención de la escritura, de la pólvora, la imprenta, la brújula junto a otros inventos como la metalurgia del hierro, del bronce, la fabricación de vidrio, la regla de cálculo, el telar automático, la vacuna contra la viruela $\mathrm{y}$ otros fueron dando un giro radical a la vida de los seres humanos en todas sus dimensiones: económicas, culturales, sociales, etcétera; potenciaron todos los procesos sistemáticos de transmisión de información y de análisis racional de las tecnologías, procesos que culminan con el surgimiento de las ciencias.

Indudablemente, la actividad tecnológica repercute en el progreso social y económico, pero su carácter comercial la direcciona hacia la satisfacción de deseos e intereses de grupos privilegiados, de aquellos que más tienen, 
lo cual degenera en un marcado consumismo que deja atrás las necesidades prioritarias de la mayoría de los seres humanos, una mayoría que queda marginada y sin posibilidades de acceso a todo aquello que se presenta como nuevo.

Da la impresión que los conceptos actuales de técnica y de tecnología se encuentran desvinculados del concepto de valor. En los últimos tiempos, el fin último de ellas se orienta al logro de la eficacia por la eficacia.

\section{Función de la tecnología en los nuevos escenarios de la sociedad}

Se puede avizorar una serie de características independientes de su función principal, de acuerdo al estudio realizado por Marshall McLuhan y B. R. Powers (1994), los objetos tecnológicos cumplen con funciones estéticas y simbólicas.

a) Función estética de los objetos tecnológicos. Parte de la creencia del usuario quien busca la belleza a través de las formas, colores y texturas, por ejemplo en las prendas de vestir, la belleza puede primar sobre las consideraciones prácticas. La ropa es el rubro tecnológico de máxima venta en el planeta porque son la cara que mostramos a las demás personas y condicionan la manera en que nos relacionamos con ellas.

b) Función simbólica de los objetos tecnológicos. Cuando la función principal de los objetos tecnológicos es la simbólica, no satisfacen las necesidades básicas de las personas y se convierten en medios para establecer estatus social y relaciones de poder (cfr. Marshall McLuhan y B. R. Powers, 1994: 26). El caso más destacado y frecuente de 
objetos tecnológicos fabricados por su función simbólica es el de los grandes edificios: catedrales, palacios, rascacielos gigantes, diseñados para empequeñecer a los que están en su interior, para deslumbrar con exhibiciones de lujo, para infundir asombro, representan símbolo del principal centro del poderío económico.

\section{Uso de la tecnología}

El uso de la tecnología está determinado por la óptica del sujeto que la utiliza y que la valora; en este sentido, desde mi punto de vista se presentan al menos tres aristas de reflexión:

1. Desde la apreciación subjetiva de un hecho (tecnológico).

2. Desde la descripción objetiva de un proceso (tecnológico).

3. Desde los resultados, productos, metas y objetivos alcanzados.

Lo anterior permite inferir que la tecnología puede ser comprendida como proceso observable, lo cual se evidencia en los diversos procesos de formación y de aprendizaje; como sistema, expresada mediante las instituciones sociales; como producto, entendida como resultado de una acción; como proceso de modificación de conductas, reflejada en las actitudes y comportamientos individuales, sociales y culturales en general.

Considero que la tarea pendiente para la epistemología de la tecnología es deslindar la definición de fenómeno tecnológico fáctico y la definición de fenómeno tecnológico axiológico. El primero pertenece al ámbito de la 
necesidad, se vincula con el hecho, con el dato real y observable, por ello es objeto de la ciencia. El segundo pertenece al ámbito de la libertad humana (propia de la moral y de la ética) y por eso mismo, es objeto de la metafísica.

Continuando con la reflexión acerca del uso de la tecnología es preciso recalcar que la técnica y la tecnología (instrumento, objeto, hecho) en sí mismas no son buenas ni malas, el uso que el sujeto -ser humano- hace de ella (dependiendo del ejercicio de su libertad) es lo que determina la calidad del juicio (ética).

Podemos sostener que el uso de la técnica y de la tecnología trae consigo ventajas pero también puede traer desventura para la humanidad; el uso que de ellas se hace es lo que provoca aspectos positivos y/o aspectos negativos, que permiten la construcción o la destrucción del ser humano y de su medio ambiente; el uso racional de ellas contribuye para el progreso individual y social. ${ }^{2}$

El uso de la tecnología puede constituirse en un problema o en una posibilidad; puede alienar, cosificar, destruir, marginar o puede potenciar la superación, el progreso, el confort, el bienestar. Por ejemplo, un arma puede usarse para matar a una persona y apropiarse de sus bienes o para salvar la vida matando un animal salvaje que atenta contra la vida humana.

Por su parte, los luditas ${ }^{3}$ consideran que las máquinas quitan puestos de trabajo a las personas, las alejan de la sana vida natural y destruyen el medio ambiente; no diferencian entre las tecnologías y las finalidades para las que son usadas, esto oscurece la discusión de la concordancia ética entre medios y fines, base de los imperativos categóricos kantianos (cfr. ibíd.: 4).

Vivimos una época donde todo es tecnología, pues inclusive los servicios personales requieren de las tecnologías para su buena prestación. 
Identificar la tecnología apropiada y realizar un uso adecuadeo de la misma, es tarea fundamental de todo ser humano de la actualidad. Pero he aquí otro problema a considerar: ¿cuándo las tecnologías ${ }^{4}$ son apropiadas?

Generalmente, se considera que una tecnología es apropiada cuando tiene efectos beneficiosos sobre las personas y el medio ambiente. A pesar de que el tema es y seguirá siendo, objeto de intenso debate, hay acuerdos acerca de las principales características que una tecnología debe tener para ser social y ambientalmente apropiada, tal como Sohn Alan lo demuestra a continuación:

- No causar daño previsible a las personas ni daño innecesario a las restantes formas de vida (animales y plantas).

- No comprometer de modo irrecuperable el patrimonio natural de las futuras generaciones.

- Mejorar las condiciones básicas de vida de todas las personas, independientemente de su poder adquisitivo.

- No ser coercitiva y respetar los derechos y posibilidades de elección de sus usuarios voluntarios y de sus sujetos involuntarios.

- No tener efectos generalizados irreversibles, aunque estos parezcan ser beneficiosos o neutros.

- La inversión de los gobiernos en tecnologías apropiadas debe priorizar de modo absoluto la satisfacción de las necesidades humanas básicas del ser humano (cfr. Sohn, Alan, 2011:3). 


\section{Fundamentos de la tecnología}

\section{El hecho tecnológico y su fundamento}

Actualmente encontramos a nuestro paso una multiplicidad de actos tecnológicos que tienden a configurar una heterogeneidad tecnológica que encubre al sujeto, que lo instrumentaliza, que lo transforma en un ser consumista o que a su vez lo objetiviza en función de intereses creados.

La tecnología se encuentra en continuo devenir, está cambiando de manera acelerada conforme a las necesidades del ser humano y a las circunstancias históricas. Para nadie es desconocido que la tecnología obedece al proceso histórico-cultural y económico de las sociedades. Por ello la tecnología siempre será contemporánea a la generación humana a la que pretende responder.

La proliferación tecnológica fomenta la ambición humana, lo pragmático cobra sentido, confunde el ser con el tener, prioriza al objeto y hasta cierto punto, olvida al sujeto. Cuando el lucro es la finalidad principal de las actividades tecnológicas, el resultado inevitable es considerar a las personas como instrumentos, como objetos o como mercaderías. Se constata que la tecnología de los últimos tiempos (a partir del positivismo) ha pretendido administrar las cosas y también la vida de los seres humanos.

Lo anterior permite inferir que al común de los mortales no les interesa reflexionar acerca de la esencia, del por qué y del para qué del acto tecnológico pues sus preocupaciones inmediatas tienen que ver con la determinación de mecanismos y la toma de decisiones acerca del qué, del cómo y del cuándo adquirir el objeto deseado a fin de evitar la posible marginación a la vista de los cambios de 
producción generados por el tiempo y por las condiciones socioeconómicas de la época histórica.

Conviene tener presente que considerar la tecnología por la tecnología es un tipo de saber reduccionista cuando no va inserto en conceptos más amplios como el concepto de educación en general, concepto a su vez inseparable de la idea de hombre. Lo importante del uso de la tecnología es "saber hacer" y "saber por qué y para qué hacerlo asî”.

De allí que, una de las tareas del filósofo de la tecnología es la aprehensión del ser, del sentido y del significado del fenómeno tecnológico. El filósofo de la educación actual deberá constatar que no resulta factible separar hombre (ántrophos), educación (paideia) y tecnología (téchne), pues las tres perspectivas son parte de una misma realidad histórica sociocultural.

A su vez, es preciso afirmar que el fundamento último de la educación y de la tecnología radica exclusivamente en el hombre, pues no podemos hablar de educación, ni de tecnología sin un sujeto histórico social situado en un contexto en el que piensa, genera, transforma, construye y actúa. Pues el significante "ser humano" lleva consigo una diversidad de manifestaciones inherentes a su propia naturaleza, no en vano, el hombre es considerado como un ser multidimensional; esto permite comprender que el concepto "ser humano" recoge y recapitula las diversas manifestaciones semióticas como: lo educando, lo técnico, lo consciente, lo inconsciente, lo filosófico, lo jurídico, lo social, lo moral, lo científico, lo religioso, lo artístico, lo político, etcétera (cfr. Fullat, 2000: 27). 


\section{Fundamento de la tecnología aplicada a la educación}

Fundamento filosófico de la tecnología aplicada a la educación. La tecnología está referida a la acción, a la práctica, a lo experimental, a lo comprobable y consecuentemente a la productividad, en este sentido corre el riesgo de convertirse en sierva de la destrucción, de intereses determinados, de atentar contra la vida del ser humano y, sobre todo, de llevar al extremo la tesis maquiavélica: "el fin justifica los medios", o de efectivizar el postulado de Hobbes: "El hombre es un lobo para el hombre".

La tecnología encuentra su fundamento filosófico en corrientes como:

- El empirismo. Sostiene que el hombre es antes sensación que razón (ontología), conocemos desde la experiencia (epistemología) y son las sensaciones las que dirigen la acción (práctica).

- El liberalismo. Para quien el individuo es más importante que el grupo (ontología), el conocimiento se inicia en cada individuo (epistemología), la actividad de cada sujeto es valiosa en sí misma (práctica).

- El naturalismo. Considera que lo espontáneo es anterior a lo aprendido a través de la civilización (ontología), conocemos desde el cuerpo (epistemología), solo es aceptable la acción espontánea (práctica).

- El pragmatismo. Según el cual, el hombre es acción exitosa proyectada al futuro (ontología), conocemos mediante la acción (epistemología), la acción eficaz es aquella que se realiza por interés (práctica).

- El positivismo. Para quien el hombre es lo que, de él, puede observarse (ontología), conocemos úni- 
camente cuando generalizamos a partir de fenómenos observables (epistemología), la acción tecnológica se basará en la observación, en la ciencia y en la técnica (práctica).

Además, existen otras corrientes que sustentan y justifican la presencia de la tecnología en la educación, entre ellas encontramos: el cientismo, el estructuralismo, el neopositivismo y el tecnicismo, todas ellas llevan implícita una determinada concepción del hombre y tienen en común el hecho de reducir el ser humano a puro dato, hecho o fenómeno. El hombre es aquello que las ciencias pueden saber de él y aquello que las tecnologías pueden hacer con él: "El ser humano carece de intimidad o, cuando menos, el sujeto, o conciencia, no cuenta" (Fullat, 2000: 279).

El discurso estructuralista considera que la realidad es puramente objetual, desaparece al sujeto o perspectiva desde la que se aborda el mundo. La falta del sujeto conlleva a sobrevalorar lo universal, la estructura (entendida como realidad abstracta, como un sistema o conjunto de objetos, donde carece de interés sus elementos concretos) a tal punto que no es posible definir la función o las variaciones de uno de ellos independientemente de la función o variaciones de los otros, así un ser vivo constituye un sistema con su medio ambiente. El estructuralismo como método resulta interesante para la comprensión y aplicación de la tecnología en los procesos educativos.

El cientismo o valor absoluto de la ciencia es un corolario del positivismo. El conocimiento positivo denuncia la invalidez de los discursos filosóficos, religiosos y por extensión éticos. Constituye fundamento de la tecnología que busca la eficacia por la eficacia, sin considerar los enfoques axiológicos o las fundamentaciones filosóficas. Considera que únicamente la ciencia puede satisfacer todas las 
aspiraciones humanas. Todo se reduce a la ciencia y a lo empírico.

El neopositivismo valora a la sensación como la única fuente del conocimiento, las leyes de la lógica son $a$ priori y tautológicas, las proposiciones tienen sentido cuando son verificables y empíricas, la verificación es tal cuando es intersubjetiva, el lenguaje propiamente con sentido es el de la física. Sostiene que solamente hay dos tipos de enunciados significativos: los analíticos y los empíricos; los enunciados no significativos son los referidos a la metafísica, a la ética, a la teología. La verdad de las proposiciones analíticas (lógicas y matemáticas) depende de la estructura formal, son verdaderas o falsas por definición. Las proposiciones empíricas son fruto de la experiencia y de la verificación.

El tecnicismo considera que "el hombre es un animal faber, una bestia fabricadora de utensilios o de medios, a fin de triunfar" (ibíd.: 286). Al hablar de técnicas no restringimos la comprensión solamente a instrumentos y a aparatos, en nuestra conceptualización también incluimos la racionalización de procesos. Encontramos a teóricos como McLuhan quien analiza la intervención tecnológica sobre el ser humano, estudió los procesos de comunicación concediendo un valor independiente a las técnicas comunicativas, entre las que se hallan las educadoras. El yo de los comunicantes desaparece. La reproducción técnica en las tareas educativas es algo que preocupa a más de un pedagogo.

Cuando educar se convierte exclusivamente en la técnica de reproducir conocimientos, hábitos y actitudes en los educandos, como sigue sucediendo en la actualidad, nos encontramos delante de pedagogías que han optado por una especie de antropología in-humanista (ibíd.: 287), aspecto que es indispensable evitar. 
McLuhan como teorizador de las técnicas de la comunicación les otorga una autonomía y un peso tal sobre los ciudadanos que éstos se convierten en instrumentos pasivos del ominipotente instrumental activo de los actuales aparatos electrónicos. Los medios de comunicación, sin duda básicos en el quehacer educativo, cuando adquiere preponderante protagonismo contemplan al hombre como un material donde reproducir esquemas, contenidos y mecanismos.

La humanidad ha atravesado según este pensador, tres etapas que se corresponden con tres principales técnicas comunicativo-reproductivas:

1. Etapa: Sociedad oral. Era prealfabética. El oído. Identificación.

2. Etapa: Sociedad escrita. Era alfabética. La vista. Escisión.

3. Etapa: Sociedad electrónica. Era electrónica. Todos los sentidos. Aldea global (ibíd.: 289).

En general, la tecnología aplicada a la educación y la misma educación deben mucho a las corrientes enunciadas, a pesar de que ellas niegan el estatuto del sujeto como tal.

Considero que para una adecuada comprensión del ser, del sentido, del significado, del qué, del para qué y del cómo de la tecnología aplicada a la educación, es necesario establecer una unidad compleja, dialéctica, sistémica y sistemática que tome en cuenta los referentes teóricos significativos y funcionales al contexto actual tanto de las filosofías de la conciencia (aquellas que valoran al sujeto, al quién ) como los aportes significativos de las filosofías del concepto (aquellas que valoran al objeto, al qué).

Con esto se superaría la tendencia deshumanizante, des-subjetivación, des-almada o in-subjetiva propia de las filosofías del concepto. 
Fundamento sociológico de la tecnología aplicada a la educación. La base sociológica de la tecnología aplicada a la educación tiene como referencia los nuevos escenarios y la diversidad de cambios y transformaciones cualitativos y cuantitativos experimentados por la humanidad a nivel histórico, tecnológico, económico, político, cultural, etcétera. Para nadie es desconocido que vivimos en una sociedad del conocimiento, de la información y con tendencia a la globalización; razón por la cual considero que en la actualidad la discusión de la tecnología aplicada a la educación se ubica en los tres escenarios concretos determinados por De Souza Silva: el contexto de la globalización, el cambio de época y el cambio del modelo cultural, revisemos estos escenarios:

a) El contexto de la globalización. La globalización es un concepto polisémico, puede ser analizado como teoría, como proceso, como estrategia y como ideología, aquí lo consideraremos de manera holística y en referencia a la complejidad de la sociedad actual.

Algunos estudiosos como De Souza Silva, José (2004) consideran que la humanidad ha experimentado tres olas de globalización:

- Primera ola de globalización. Entre fines del siglo XV y mitad del siglo XVIII, fue financiada por el capital mercantil. Lo agrario es la base del comercio mundial. Se apoya en la tecnología de la navegación.

- Segunda ola de globalización. Entre la segunda mitad del siglo XVIII y final de la Segunda Guerra Mundial, fue financiada por el capital industrial. El industrialismo es la base del comercio mundial, se apoya en la tecnología material: mecánica, química y eléctrica. 
- Tercera ola de globalización. Después de la Segunda Guerra Mundial, diferentes fenómenos sociales, económicos, políticos e institucionales, y algunos avances científicos y tecnológicos forjaron las condiciones que permiten al capital financiero liderar la ola contemporánea de globalización. El informacionalismo es la base para su desarrollo; su soporte llega a través de la tecnología intelectual: la teoría-tecnología de la interpretacióny la codificación de conocimiento teórico para la aplicación práctica (cfr. De Souza Silva, 2004: 7-8)

Estas olas de globalización se diferencian entre sí por los métodos, técnicas y procedimientos; por la naturaleza de las tácticas y estrategias que fueron empleadas; por el perfil de sus protagonistas; por el contexto geográfico de los cambios generados; por los ámbitos temáticos de sus impactos y por la intención que las provoca.

b) El cambio de época. Diversos autores, entre ellos, José de Souza Silva consideran que estamos viviendo más un cambio de época que una época de cambios. De acuerdo a De Souza Silva, José (2001, citado por Abaunza, 2009: 1), los cambios que están operando son los siguientes:

1. La revolución de la tecnología de la información alteró las relaciones de producción. La información se volvió insumo y producto. Los productos, procesos y servicios más relevantes son los relativos al conocimiento. La productividad se deriva de la innovación tecnológica y la competitividad de la innovación institucional. El trabajador del 
conocimiento reemplaza al trabajador manual. El capital es global mientras que el trabajo es local.

2. También hay cambios en las relaciones de poder. El conocimiento lidera la fuerza y el dinero; entra en crisis el Estado-Nación, se reduce su soberanía, su autonomía y se instalan mecanismos supranacionales; la ideología del Estado es reemplazada por la ideología del mercado; se globaliza la sociedad civil para ejercer su influencia sobre cuestiones generadas a partir de la revolución sociocultural.

3. La forma como se vive la experiencia humana está bajo transformaciones profundas. El movimiento feminista cuestionó la autoridad del patriarcado y propuso una nueva relación entre los géneros (nuevas formas de sexualidad). Las nuevas TIC y en particular el Internet hacen posible un nuevo mundo, donde el tiempo histórico no cuenta, el espacio geográfico desaparece y las relaciones sociales cara a cara son innecesarias. La experiencia humana y los bienes culturales son comercializados.

4. La cultura se está virtualizando. La realidad virtual se está imponiendo sobre la realidad real, el tiempo es atemporal, el espacio inmaterial, la historia sin secuencias. Valores e intereses son construidos sin referencia al pasado ni al futuro. Lo que aparece en las pantallas es lo real, no lo que experimentamos. Los padres prefieren comprar juegos electrónicos a sus hijos en vez de interactuar con ellos. La generación "punto com", corre el riesgo de asumir que no será necesario caminar para conocer el mundo y transformarlo (cfr. De Souza Silva, 2001: 23-25, citado por Abaunza Gutiérrez, 2009: 3) 
Rodríguez retomando a Percherón (1985) identifica algunos cambios en la política de las sociedades industriales, entre ellos: la transformación de los partidos políticos en maquinarias electorales; la pérdida del carácter militante de los sindicatos y de las agrupaciones religiosas; la transformación de la enseñanza institucionalizada como un espacio donde se presentan una diversidad de opciones; el enfrentarse a una variedad de modelos y enfoques; una nueva ética social que invita a cada individuo a tomar sus propias decisiones (Rodríguez, 1988: 54).

Por su parte, Nobert Lechner (1997) sostiene que la época actual ha erosionado los mapas cognitivos y en particular las coordenadas del tiempo y del espacio. Todas las variables socialmente construidas se han redimensionado; las escalas se han redefinido; los límites se han reestructurado, las fronteras son tenues, la globalización produce segmentación, los límites entre lo político y lo no político se han tornado confusos y evidencian las dificultades que tiene la política en la fijación de límites; las distancias se alteraron (cfr. Lechner, 1997: 15-17).

El tiempo se ha transformado, se ha acelerado, debilitando la relación entre pasado, presente y futuro, perdiendo la perspectiva histórica; el presente se ha vuelto omnipresente, socavando la tensión entre duración e innovación, reemplazándola por un dispositivo de repetición; lo inmediato se vuelve protagónico; las temporalidades se diferencian y cada ámbito desarrolla dinámicas y ritmos propios que obedecen a programaciones internas (cfr. Abaunza Gutiérrez, 2009: 1).

Entre los cambios que modifican una época podemos mencionar: la distribución de la riqueza y la lucha contra la pobreza, la ampliación del espacio de solidaridad social y responsabilidad pública; la demanda del carácter público (de la educación, la salud y los distintos espacios 
públicos) como ámbitos de democratización; la demanda de marcos regulatorios para la protección de los derechos del usuario y del consumidor; la demanda de marcos regulatorios de las economías privadas y de un poder judicial independiente, etcétera (Cfr. De Souza Silva, 2004: 18).

Según Manuel Castells (1996), una época histórica cambia cuando se transforma de forma cualitativa y simultánea las relaciones de producción, las relaciones de poder, la experiencia humana y la cultura (Citado por Lazo, 2006:1).

Por lo general, se considera que la revolución industrial ${ }^{5}$ representa el último cambio de época que trajo consigo cambios cualitativos en las relaciones de producción; ${ }^{6}$ cambios cualitativos en las relaciones de poder; ${ }^{7}$ cambios cualitativos en la experiencia humana; ${ }^{8}$ cambios cualitativos en la dimensión cultural. ${ }^{9}$

En definitiva, los cambios anteriores generan transformaciones cualitativas en todas las dimensiones del ser humano: en las relaciones de producción, en las relaciones de poder, en la experiencia humana, en la cultura; etcétera. El conocimiento se aplica sobre el conocimiento existente y produce más conocimientos, es la dinámica de los últimos tiempos. La productividad (derivada de la innovación tecnológica) y la competitividad (derivada de la innovación institucional y de la capacidad gerencial) se convertirán en los referentes fundamentales de la economía de los pueblos.

La revolución en la tecnología de la información también viabiliza otras revoluciones tecnológicas, como la robótica, nuevos materiales, nanotecnología, ingeniería genética (o biogenética, biotecnología), etcétera. También están cambiando las relaciones entre capital y trabajo: en su base, el capital es global y coordinado, como regla, el trabajo es local e individualizado; el asenso de un nuevo régimen 
de acumulación de capital, apoyado por la tecnología de la información, está transformando las relaciones de poder; el conocimiento lidera la fuerza y el dinero es la ecuación del poder; proliferación de movimientos ambientalistas, de género, mundos virtuales (cfr. De Souza Silva, 2004: 25-26); nuevas formas de vivir y relacionarse con los otros, con la sociedad y con la naturaleza; son algunos cambios que evidencian una sociedad de-secuenciada en la que proliferan nuevos riesgos, fuertes crisis de valores éticos y generación de nuevos paradigmas.

Todo lo antes mencionado conlleva una serie de procesos globales que contribuyen al cambio de época. Cuatro procesos son los más relevantes: la construcción de un nuevo régimen de acumulación de capital para la denominada época emergente o época de la información y del conocimiento; el establecimiento de un Estado-red supranacional; constitución de un nuevo escenario con nuevos protagonistas, con formas de pensar, ser y actuar diferentes y semejantes, un nuevo mundo donde ricos y pobres coexistan en una unidad dialéctica; y la emergencia de un nuevo modo de generación de conocimiento (cfr. ibíd.: 34-37)..

c) El cambio del modelo cultural. El modelo cultural va experimentando diversas transformaciones que configuran un nuevo horizonte en las diferentes manifestaciones de la sociedad: en la política, en la educación, en la religión, etcétera.

En los momentos actuales se visualizan con claridad una serie de turbulencias financieras, tensiones internacionales, presiones migratorias, ataque terroristas, conflictos inter-étnicos, modificaciones profundas de la estructura de las economías (cfr. Burcet, 2011: 1), implicaciones del aparecimiento de la nueva tecnología, generación de nuevo conocimiento, proliferación de brotes de violencia, tensio- 
nes interculturales, conflictos políticos y religiosos que van configurando un nuevo paradigma cultural.

Más allá de la economía, la tecnología, la ecología y la ciencia, la cohabitación cultural se convertirá en uno de los problemas más característicos del siglo XXI (ibíd.: 4), lo cual obligará a desarrollar habilidades y destrezas que permitan enfrentar los nuevos desafíos; obligará a buscar mecanismos diversos para responder a los nuevos requerimientos de la cultura de la humanidad (cfr. ibíd.: 6). Esto exigirá nuevos y vastos conocimientos, métodos y estrategias para afrontar y resolver los conflictos que se avizoran.

Es claro que la solución a los problemas de cohabitación cultural no radica en la adopción de un solo tipo de cultura, ni en la disposición de diversas vías especializadas para cada tipo de cultura, lo ideal es responder a las necesidades específicas de cada una sin olvidar a la cultura universal, nos atreveríamos a decir que la solución estaría "en actuar localmente pero siempre pensando globalmente", al estilo de la propuesta realizada por Morin.

Desde esta perspectiva, concordando con Burcet (2011), tomando como referencia los acontecimientos ocurridos durante los últimos tiempos, y de acuerdo a su capacidad para asimilar la novedad, podemos citar seis tipos diversos de cultura: culturas primigenias cerradas; ${ }^{10}$ culturas pre-industriales expuestas superficialmente a influencias externas; ${ }^{11}$ culturas en proceso lento de modernización económica; ${ }^{12}$ culturas en proceso rápido de modernización económica; ${ }^{13}$ culturas en estado avanzado de modernización económica; ${ }^{14}$ culturas que podrían trascender el estadio post-industrial. ${ }^{15}$

Todas estas culturas han facilitado los cambios más rápidos registrados en los últimos tiempos.

La coexistencia de todas estas culturas en un mundo cada vez más interconectado y globalizado, desencadena 
nuevos problemas que deberían ser analizados, afrontados y resueltos.

En definitiva, se puede afirmar que el cambio del modelo cultural está signado por características básicamente económicas, tecnológicas y científicas que inciden directa o indirectamente en todos los campos del accionar humano, entre ellas podemos mencionar:

1. Ampliación y diversificación de la oferta del mercado. El ser humano es consumidor y responde a las exigencias del desarrollo de las tecnologías.

2. Surgimiento de las nuevas tecnologías de la comunicación y la información. Prioriza el lenguaje audiovisual, la multimedia y el hipertexto como formatos distintos de conocimientos, como maneras distintas de conocer la realidad. Se perciben distintas formas de organizar y de estructurar la comprensión del mundo; distintos modos de estar en el mundo.

3. Transformaciones en la generación del conocimiento. El paulatino desplazamiento de la escritura tradicional hacia lo lúdico, hacia lo audiovisual y hacia los medios en general determina nuevas fuentes de conocimiento, nuevas formas de enseñanza y de aprendizaje; el conocimiento enciclopédico es desplazado por un conocimiento significativo que se construye permanentemente.

4. Modelo cultural paradigmático. Los medios de comunicación han pasado a ser el vértice de la construcción de la cultura contemporánea. El lenguaje audiovisual es el lenguaje preferencial de las nuevas sensibilidades que surgen de la interac- 
ción con las nuevas tecnologías de información y comunicación.

5. Desplazamiento de la socialización vertical a la socialización lateral y lúdica con la inclusión de los medios. En los procesos de aprendizaje y de orientación se visualiza una combinación entre lo humano (docentes, padres de familia, amigos, entre otros) y lo tecnológico (televisión, juegos electrónicos, internet y sus herramientas).

6. Entorno social. Necesario para que las personas puedan desarrollar su potencial, su productividad y estar en condiciones de llevar una vida digna; es un entorno social que amplía las opciones, las capacidades, las habilidades y las destrezas de las personas y que contribuye con la expansión de la libertad, del pensamiento y de la acción.

\section{Problemas y saberes de la tecnología}

\section{Problemas de la tecnología}

El concepto tecnología involucra la formulación de cuestiones y problemas fundamentales como los siguientes:

- Problema ontológico. Intenta responder al ser, la esencia y la existencia misma de la tecnología en cuanto tal. La aproximación ontológica a la tecnología permite una incursión en el ser mismo de esa realidad tecnológica para detectar sus cualidades intrínsecas, sus rasgos más privativos y esenciales. 
- Problema gnoseológico. Pretende resolver acerca de cuestiones como el origen, la esencia, la forma, la verdad y los límites de la tecnología. Analiza la relación que se presenta entre el sujeto cognoscente (agente, creador, productor, innovador, activo, consciente) y el objeto cognoscible (hecho, dato, fenómeno, lo dado, el contexto o la realidad construida).

- Problema epistemológico. Averigua acerca de los paradigmas tecnológicos, la estructura interna, la metodología, el sistema de la tecnología y las relaciones con la ciencia.

- Problema axiológico. Se pregunta acerca de la operativización de los valores en el uso de la tecnología, reflexiona acerca de la libertad, la justicia, la ética, la colaboración, etcétera.

- Problema teleológico. Se cuestiona acerca de la finalidad o fines de la tecnología.

Los problemas antes señalados no pueden comprenderse sin la interacción de factores como los siguientes: Sujeto que observa, que asimila, que crea y que recrea.

Objeto (realidad, contexto, dato o fenómeno) que proporciona características y propiedades al sujeto.

Pensar, imaginar, razonar, conocer, entendido como actividad interna realizada por el sujeto agente.

Pensamiento determinado proyectado u objetivado en un dato, en un hecho, en una acción o en una tecnología.

Expresión de la idea, del proceso y del resultado a través de la conceptualización, la teorización y la generalización. 
La tecnología como realidad y como conocimiento. Filosóficamente hablando la tecnología puede ser entendida como realidad y como conocimiento, sin embargo, desde el primer sentido corre el riesgo de reducirse a una mera facticidad pura y desde el segundo sentido, la tecnología puede reducirse a una serie de teorías fragmentarias condicionadas por el contexto y aisladas de toda praxis social efectiva.

Lo que la tecnología es en verdad tanto respecto de su esencia fáctica como de la no-fáctica (es decir, de la que aún no ha llegado a ser en su totalidad) es y seguirá siendo un constructo indefinido del ser humano y del contexto en el que surgen.

El aparecimiento de una tecnología siempre será nueva para la época en la que surge; se presentará como una superación de lo tradicional; pero su duración es temporal, pues cada vez se volverá insuficiente a las nuevas circunstancias y exigencias del contexto.

De allí que, la verdadera génesis de la tecnología no es un factum del comienzo sino un intento en camino y un problema del final.

La tecnología lleva consigo nuevas maneras de transformar el mundo, nuevas formas de entender el entorno y nuevos mecanismos de instalarse o situarse en el mundo. Esto da como resultado una nueva configuración del mundo. Y como parte del mundo que se transforma, el hombre a través del trabajo físico e intelectual se convierte en el principal elemento de mediación histórica entre el pasado, el presente y el futuro.

Esta mediación histórica implica una unidad dialéctica entre lo objetivo y lo subjetivo, entre la realidad concreta y el pensamiento, entre la naturaleza y el hombre. Por eso, una filosofía de la tecnología debería conjugar la teoría y la praxis como una totalidad estructurada, dinámica y compleja. 
La tecnología como realidad y como conocimiento en los últimos tiempos considera al mundo de modo instrumental, utilitarista y pragmático, como una especie de negocio por construir.

Naturaleza de la realidad y del conocimiento tecnológico. Es importante preguntarse acerca del sentido y del significado real de la tecnología, esto nos lleva a explicar acerca de la naturaleza de la realidad y del conocimiento tecnológico.

Una de las características más relevantes de la tecnología actual y de la filosofía de la tecnología (cuyo objetivo consiste en analizar la naturaleza, las condiciones y el alcance del conocimiento tecnológico) es la exigencia y el propósito de hacer de la tecnología un conocimiento y un hecho, una teoría y una praxis contemporánea.

El saber tecnológico debe versar sobre nuestro propio presente, sobre la realidad y el tiempo en los que estamos inmersos. La tecnología concierne a nuestra existencia social, responde al tiempo y a la realidad de nuestra praxis, surge de nuestras decisiones, origina nuevas elecciones y define nuestros comportamientos.

En este sentido, cualquiera que sea el momento al que se aplique el interés cognoscitivo del filósofo de la tecnología, éste siempre deberá proporcionar una visión del presente.

Para acercarse a la naturaleza de la realidad y del conocimiento tecnológico se podría acudir al auxilio de los siguientes métodos:

a) Al método fenomenológico, iniciando por una actitud natural entendida como el enfrentamiento del sujeto con la realidad tecnológica, procediendo a una descripción de esa realidad, tal y 
cual ella se presenta por sí misma ante nuestra conciencia, esto es, sin interferencias, sin prejuicios ni suposiciones teóricas de ninguna especie; avanzando con la determinación del eidos de la tecnología hasta concluir con una verdadera reflexión fenomenológica, con tendencia a la generalización o teorización respectiva.

b) $\mathrm{Al}$ método dialéctico moderno para comprender que la tecnología en sí misma se nos presenta como un proceso constante, como un devenir temporal que va sustituyendo incesantemente instituciones, creencias, personalidades, situaciones, culturas, etcétera.

Hablar de la naturaleza de la realidad y del conocimiento tecnológico implica comprender que éstos constituyen parte de una realidad dinámica y compleja en la cuál es difícil discernir alguna permanencia, algunos nexos firmes o cierta legalidad estable.

El ser humano, la educación y la tecnología constituyen un problema en sí y por sí mismo. El ser humano es un ser inacabado, inconcluso, un imperfectum es un proyecto que se construye a cada instante y, por tanto, es un problema sin resolver. La información que recibimos de la historia, la que entrega la sociología, la que genera la educación y la experiencia personal, nos aseguran que el conjunto de actos tecnológicos, no logra la solución total de las dificultades humanas.

En este sentido, la educación por más ayudada que se encuentre por la tecnología, siempre será una tarea indefinida inherente a todo sujeto racional, consciente, cognoscente y educando. ${ }^{16}$ Del mismo modo, la tecnología 
analizada en su globalidad histórica constituye un quehacer interminable propio de la praxis humana.

Octavi Fullat, sostenía que: "lo específico del hombre no reside en que pueda educarse -también pueden el chimpancé del circo y el can familiar-, sino en que tiene que educarse,..." (Octavi, 2000:30). En fin, "educar es producir al ser humano" (ibíd.: 29), es hacerse mediante la educación.

De allí que tanto el ser humano como la tecnología y la educación constituyen en sí problemas perpetuos que tienden a recorrer caminos similares, una diversidad de trayectos con multiplicidad de obstáculos a los que intentan resolver.

\section{Saberes integradores de la tecnología}

Reflexionando acerca del proceso general de construcción de proposiciones y de saberes tecnológicos, en función del telos (siguiendo a García Carrasco y García del Dujo, en el ámbito pedagógico), se podrían determinar las siguientes secuencias estructurales:

"1. "Algo debe ser conseguido.

2. Existen teorías científicas que pueden ser utilizadas como recursos explicativos o de legalidad en el ámbito de hechos comprometidos por las metas propuestas.

3. Determinación de secuencias de acción,... entre cuyos efectos deben quedar incluidos los propósitos intentados..." (García Carrasco y García Del Dujo, 1996: 75)".

De lo antes expuesto, infiero que son cuatro núcleos los que configuran el hecho tecnológico, pues no puede haber tecnología sino hay una teoría, una filosofía, una 
axiología o una metodología que la respalde. En tal virtud, me atrevería a establecer que las disciplinas encargadas de sistematizar la acción tecnológica son las que a continuación se detallan:

- Teoría de la Tecnología. Consiste en la descripción y en la explicación de todo cuanto ha sucedido y sucede en los procesos tecnológicos, en la esfera de la praxis, en el sentido en que éstos constituyen aprendizajes de informaciones, de actitudes, de habilidades. La teoría de la tecnología determina el marco conceptual, crítico y normativo que guiarán las acciones humanas.

- Filosofía de la Tecnología. Entendida como un saber globalizador, analítico y comprensivo de los procesos tecnológicos que facilita presupuestos antropológicos, epistemológicos y axiológicos, con miras a la producción de análisis críticos e interpretativos. Proporciona las categorías fundamentales para determinar el por qué y el para qué de la tecnología.

- Axiología de la tecnología. Establece todo un conjunto de valores necesarios para determinar la calidad de las acciones humanas en relación a la creación y al uso de la tecnología.

- Metodología de la tecnología. Proporciona una serie de métodos, técnicas, instrumentos, recursos, procedimientos, herramientas, tácticas y estrategias para hacer un uso adecuado de la tecnología. Esta disciplina se convierte a la vez en la síntesis integradora de todos los presupuestos antropológicos, epistemológicos, axiológicos, sociológicos, etc. 


\section{Impacto de la tecnología}

La elección, desarrollo y uso de las tecnologías puede tener impactos muy variados en todos los órdenes del quehacer humano y sobre la naturaleza.

Sobre el impacto cultural de una tecnología, en su obra: "La aldea global en la vida y los medios de comunicación mundiales en el siglo XX", Herbert Marshall McLuhan y B. R. Powers, establecen cuatro preguntas específicas para cada tecnología particular:

- ¿Qué genera, crea o posibilita?

- ¿Qué preserva o aumenta?

- ¿Qué recupera o revaloriza?

- ¿Qué reemplaza o deja obsoleto? (cfr. McLuhan y Powers, 1994: 21-29)

Este cuestionario podría ampliarse para identificar mejor los impactos positivos o negativos, de cada actividad tecnológica tanto sobre las personas como sobre su cultura, su sociedad y el medio ambiente. Solivérez (2003: 24) sugiere los siguientes impactos:

- Impacto práctico: ¿Para qué sirve? ¿Qué permite hacer que sin ella sería imposible? ¿Qué facilita?

- Impacto simbólico: ¿Qué simboliza o representa? ¿Qué connota?

- Impacto tecnológico propiamente dicho: ¿Qué objetos o saberes técnicos preexistentes lo hacen posible? ¿Qué reemplaza o deja obsoleto? ¿Qué disminuye o hace menos probable? ¿Qué recupera o revaloriza? ¿Qué obstáculos al desarrollo de otras tecnologías elimina? 
- Impacto ambiental: ¿El uso de qué recursos aumenta, disminuye o reemplaza? ¿Qué residuos o emanaciones produce? ¿Qué efectos tiene sobre la vida animal y vegetal?

- Impacto ético: ¿Qué necesidad humana básica permite satisfacer mejor? ¿Qué deseos genera o potencia? ¿Qué daños reversibles o irreversibles causa? ¿Qué alternativas más beneficiosas existen?

- Impacto epistemológico: ¿Qué conocimientos previos cuestiona? ¿Qué nuevos campos de conocimiento abre o potencia? (cfr. Solivérez, 2003: 24)

Como la introducción de nuevas tecnologías modifica y reemplaza funciones humanas, cuando los cambios son suficientemente generalizados pueden modificar también las relaciones humanas, generando un nuevo orden social.

Las tecnologías no son independientes de la cultura, integran con ella un sistema socio-técnico inseparable. Un ejemplo de la vinculación entre la evolución tecnológica y la social es el libro: Los orígenes de la civilización, del historiador Vere Gordon Childe.

Las tecnologías disponibles en una cultura condicionan su forma de organización, así como la cosmovisión de una cultura condiciona las tecnologías que está dispuesta a usar.

\section{Incidencia de la tecnología en la visión del mundo}

El ser humano se enfrenta con el mundo de dos maneras: conociéndolo y actuando en y sobre él para transformarlo. En el primer caso elabora, construye enunciados de la realidad, calificándolos a unos verdaderos y a otros falsos; en este sentido nos estamos refiriendo a un saber de 
tipo cognoscitivo, racional y reflexivo. En el segundo caso, produce juicios de valor, señalando que tal acción es buena o mala, que algo es bello o feo, que aquella actividad es eficaz o simplemente que no lo es; en este sentido nos encontramos ante un saber práctico, pues implica "tomarse la vida con filosofía" para poder comprender y actuar en el mundo. En los dos casos, el ser humano dispone de la capacidad para analizar, para dar sentido y significado a las construcciones teóricas y a la praxis cotidiana, aspecto que sigue siendo una tarea indefinida.

Generalmente, se ha concebido que no hay acto tecnológico sin valoraciones; éstas no son posible sin algún modelo de lo humano; dichos modelos se inscriben en una cosmovisión determinada. Y son tres revoluciones: una sociocultural, una tecnológica y otra económica las que van configurando una nueva época, la denominada sociedad de la información y del conocimiento.

Tomando como referencia el pensamiento de De Souza Silva (2001), procedemos a presentar la caracterización de cada una de las revoluciones antes referidas:

- La revolución sociocultural (desde 1960) está determinada por la proliferación de movimientos socioculturales (feministas, ambientalistas, de derechos humanos, justicia y equidad social, étnicos, entre otros) que desafían a la civilización occidental y los valores de la sociedad industrial de consumo (cfr. De Souza Silva, 2001:3).

- La revolución económica (finales de 1970) iniciada por los conflictos en cuanto a los precios del petróleo que da lugar a una clara crisis económica que revela el agotamiento del régimen de acumulación de capital de la época del industrialismo y propicia la formación de un régimen de 
acumulación de capital, de naturaleza corporativa, de carácter transnacional, de alcance global y dependiente de la información (cfr. ibíd.).

- La revolución tecnológica (mediados de 1970) se inicia en torno a la tecnología de la información, influencia en otras revoluciones científicas y tecnológicas y penetra a la mayoría de los medios y formas de comunicación. La dimensión microelectrónica de esta revolución hace posible la concepción de redes virtuales capaces de comprimir y eventualmente desmaterializar el tiempo histórico y el espacio geográfico (cfr. ibíd.: 2-3). Los cambios derivados de esta revolución tecnológica (la formación de redes virtuales, la integración electrónica de formas (texto, sonido e imagen) y medios de comunicación; la creación de oficinas-en-red, los libros virtuales, los espacios inteligentes y el terrorismo cibernético, viabilizan muchos de los cambios derivados de las revoluciones sociocultural y económica y evidencian una vez más una visión mecánica de mundo (cfr. ibíd: 4).

No obstante, es necesario resaltar que ninguna de estas revoluciones en sí y por sí logrará cambiar una época; son los impactos de ellas los que generan las condiciones necesarias para que se den los cambios.

El nuevo contexto sugiere que estamos enfrentando un nuevo modelo o paradigma de tipo emergente caracterizado por una nueva visión del mundo, de la naturaleza, del hombre y de la sociedad en general que determinan una nueva constelación de la historia con todas sus dimensiones.

Cada época histórica determina el aparecimiento de una nueva visión de mundo; moldea nuestra percepción 
de la realidad, nuestras decisiones y acciones en el quehacer cotidiano.

Una visión de mundo ${ }^{17}$ es una ventana conceptual, a través de la cual interpretamos el mundo para comprenderlo y para transformarlo; todos somos presionados a cambiar de lentes de acuerdo a las circunstancias y de acuerdo al contexto. Nuestra visión de mundo condiciona nuestros modelos mentales, a través de los cuales observamos, sistematizamos, interpretamos y aportamos significado a nuestra propia experiencia en el mundo (ibíd., 2004: 14).

Las tres revoluciones (ya mencionadas) generan tres visiones de mundo: cibernética, mercadológica y contextual, que coexisten bajo una jerarquía de valores, premisas y objetivos establecidos por aquella visión de mundo que será hegemónica y prevalecerá sobre las demás.

Así, en el contexto actual se visualizan estas tres visiones de mundo que a decir de José De Souza Silva (2004) se sitúan entre una época que agoniza en su ocaso y otra que lucha por establecerse, a continuación nos referiremos brevemente a cada una de ellas:

1. La visión cibernética de mundo, es una visión mecánica que se estableció junto con la ciencia moderna. Tiene sus bases teóricas en Galileo, Descartes y en Newton. Desde esta visión, el mundo pasó a ser percibido como una máquina sin sentimientos, donde la razón mecánica excluye a la emoción humana. Sin espacio para valores morales ni principios éticos, este reinado de la racionalización es "habitado" por piezas del engranaje que permiten funcionar a la máquina.

La historia no existe o no es relevante para la máquina; el pasado y el futuro están asociados a la idea de progreso expresado por un conjunto de soluciones mecánicas. 
El contexto corresponde a "la" realidad "objetiva", que existe independiente de nuestra percepción, decisiones y acciones.

La organización es una máquina que transforma insumos en productos; es una máquina dinamizada por el recurso humano que la manipula y que es capaz de ejecutar tareas rutinarias, replicar "recetas" e imitar comportamientos, pero que no es capaz de pensar ni de crear.

Esta visión selecciona la eficiencia productiva como la máxima referencia para el proceso de innovación.

Los conceptos propuestos a partir de la metáfora de la máquina son: progreso, eficiencia, control, cuantificación, predicción, producción, productividad, engranaje, recursos humanos, resultados, metas, impactos, disciplina, orden, equilibrio, cadena de comando, redes (electrónicas) (cfr. ibíd.: 14-15). Desde esta visión mecánica del mundo, la obsesión por la eficiencia continuará con el proceso de deshumanización.

2. La visión mercadológica de mundo, se trata de una visión económica del mundo que siempre estuvo presente, desde los tiempos en que el capital mercantil impulsó el comercio entre los continentes. Tiene sus bases teóricas en la ideología del mercado y en el régimen de acumulación del capital. Desde esta visión, el mundo es percibido como un mercado sin sociedades, donde las transacciones comerciales prevalecen sobre las relaciones sociales. Este es un mundo habitado por proveedores, productores, intermediarios, procesadores, vendedores, industriales, intermediarios, banqueros, competidores, consumidores, clientes, inversionistas, etcétera. En este mundo darwiniano, la existencia es una lucha en la que solamente el ser más competitivo tiene las posibilidades de sobrevivir.

La historia no es relevante para el mercado, el pasado es apenas una reconstrucción cronológica, de carácter 
evolucionista, de los hechos objetivos cuantificables. El futuro, se restringe a las tendencias del mercado.

Es un contexto comprendido principalmente a través de las leyes naturales del mercado -oferta y demanda, y de la premisa de que los individuos son egoístas y con tendencia a actuar movidos siempre por sus intereses particulares. La realidad "objetiva" considerada relevante es la realidad económica, que puede ser resumida en la realidad del mercado, con todas sus necesidades e implicaciones.

La organización es un proveedor de productos y servicios para este mercado. La dinámica de este proveedor particular depende de su "capital humano"-una cosa, y de su "capital intelectual"- una mercancía; su fuente de motivación es el lucro máximo en el presente, su finalidad última es aportar a la acumulación de capital, y su fuente de inspiración y referencia en cualquier tiempo es únicamente el mercado.

La metáfora del mercado propia de esta visión de mundo, traslada para las realidades sociales, económicas, políticas e institucionales de la sociedad la lógica evolucionista de la realidad "natural", donde la existencia es una lucha por la sobrevivencia.

Bajo esta visión económica de mundo, la existencia continuará como una lucha por la sobrevivencia, bajo el credo de la competitividad, que trasforma la realidad en un espacio donde solo existen competidores (cfr. ibíd.: 15-16).

3. La visión contextual de mundo, es una visión holística del mundo donde éste es visto como un sistema complejo y dinámico, con múltiples dimensiones y funciones interconectadas (espacial, temporal, ecológica, social, económica, política, institucional, ética, estética) y es constituido por una diversidad de entidades vivas interrelacionadas, incluyendo la especie humana organizada en 
sociedades. Emerge de la interacción entre los actores que denuncian la vulnerabilidad del planeta y proponen la práctica sistémica de un desarrollo hacia la sostenibilidad de todas las formas de vida (cfr. ibíd.: 17).

Las dimensiones del tiempo se encuentran interconectadas de modo similar a las diferentes manifestaciones humanas, sociales y culturales. Existen "contextos” y realidades socialmente construidas por las decisiones y acciones derivadas de las diferentes percepciones de la realidad. En este sentido, el contexto es un espacio especial de desarrollo, donde interactúan sociedad, cultura y naturaleza. Desde un compromiso con la totalidad, la tecnociencia ${ }^{18}$ es un sistema facilitador de cambio y desarrollo, actúa bajo un control social ampliado, en el contexto de su aplicación e implicaciones: ciencia con conciencia, para la sociedad y la vida en el planeta. Esta visión del mundo no es un sistema en equilibrio, sino en constante proceso de cambio.

Bajo la visión holística de mundo, la complejidad de la realidad emerge como un sistema dinámico y contradictorio, donde solo la solidaridad puede promover las negociaciones necesarias para construir la sostenibilidad para todas las formas de vida en el planeta (cfr. ibíd.: 16-18).

Es preciso recordar que, ninguna visión de mundo llega a ser practicada de forma pura, pues, hasta la visión dominante dentro de una época es forzada a co-existir con aspectos, componentes, elementos e influencias de otras visiones de mundo.

\section{Implicaciones de la tecnología en la educación}

En los últimos tiempos, la tecnología de la información y de la comunicación (tema de interés en los procesos educativos) ha creado un nuevo continente: el continente digital, donde la Internet es un puerto virtual importante en la era del acceso, del conocimiento y de la información. 
Vivimos una época donde el concepto "red" posee consecuencias prácticas para la determinación estructural de la nueva sociedad que exige no solamente el procesamiento de la información sino que también exige el procesamiento del saber.

En tal virtud, el llamado nuevo continente proporciona nuevas herramientas e instrumentos y exige del ser humano un adecuado conocimiento, estrategias para la selección, para el procesamiento y para la utilización racional de las mismas. Es aquí donde la educación deberá cumplir su cometido.

La educación con auxilio de la tecnología deberá proponerse como tareas: concientizar acerca del uso de los medios de información y de la comunicación; proporcionar técnicas, tácticas y estrategias para resolver problemas; potenciar la capacidad comunicativa; promover sujetos con principios y valores; propiciar el desarrollo del espíritu crítico, analítico, reflexivo, constructivo, propositivo; generar seres autónomos, libre pensadores, emprendedores capaces de responder a las nuevas exigencias sociales, etcétera. Al contrario, quien no se aproxime al conocimiento y al uso de la nueva tecnología corre el riesgo de quedar marginado y de ingresar en las filas del analfabetismo digital.

Para cumplir con las tareas mencionadas, la educación con apoyo tecnológico deberá superar una serie de dogmas, falsas creencias, suposiciones y/o mitos que obstaculizan el logro de una educación holística (íntegra e integral). A continuación esbozaré estos dogmas y/o falsas creencias:

El dogma de la ausencia inicial de conocimientos (incluidos los tecnológicos). Los estudiantes son como una hoja en blanco, desprovistos de conocimientos e ideas hasta que el docente le proporciona la información necesaria y lo transforma en un ser ilustrado. 
El dogma de la objetividad y de la experimentación. Los estudiantes son objetivos, prácticos, pragmáticos, fríos y calculadores, no consideran los sentimientos y las emociones.

El dogma del conocimiento absoluto y permanente. La suposición de que el conocimiento es sagrado, estable, exclusivo e inmutable.

El dogma de la mejor fórmula. La creencia de que la mejor fórmula para resolver un problema es la proporcionada o ideada por el docente.

El dogma del aprendizaje como una actividad intelectual pura. El aprendizaje es considerado solamente como una actividad interna, cognitiva, aislada y separada.

El dogma de aprender versus hacer. Supone que mientras se hace algo, no se puede estar aprendiendo y viceversa.

El dogma de que la educación auxiliada por la tecnología genera una educación de calidad. Creer que la mera incorporación y utilización de la nueva tecnología en el aula es garantía de procesos educativos de calidad.

Continuando con la reflexión acerca las implicaciones de la tecnología aplicada a la educación, se podría afirmar que ésta abre nuevas perspectivas en la práctica pedagógica, modifica las conductas de los seres humanos, transforma su ser y estar en el mundo, genera horizontes de sentido de posibilidades, de significados y de cosmovisiones diferentes.

Las implicaciones del uso de las redes tecnológicas en la educación son múltiples, involucran innumerables cambios cuanti y cualitativos, cambios en las concepciones del tiempo y del espacio, cambios en la forma de enseñar y de aprender que configuran un entorno social, laboral, educativo, cultural diferente; amplía las posibilidades de aprender de modo diversificado y autónomo; potencia la produc- 
ción de conocimientos y el desarrollo de la creatividad, crea procesos integrados e integrales en diferentes situaciones de aprendizaje; propicia cambios en las relaciones de poder y de control; cambios de roles que garantizan el protagonismo del estudiante como constructor de su conocimiento, con competencia para cuestionar, asimilar, comparar, argumentar, indagar, interpretar y producir; promueve cambios en los modos de acceder a la información y en la construcción del conocimiento; cambios en hábitos y costumbres personales y sociales; en fin, cambios en todos los niveles y dimensiones humanas.

Es de sentido común saber que a cada pedagogía corresponde un tipo de educación y a cada educación un tipo de tecnología; al ser la pedagogía un proceso de intervención en la formación del ser humano debe contribuir para la transformación individual y social.

El humanismo, la Pedagogía Crítica y el constructivismo histórico social deberán ser los que den sentido y significado al uso de la tecnología aplicada a la educación actual.

Desde mi óptica, los principios fundamentales que permitirían la operativización de los postulados propios de las corrientes antes mencionadas son los siguientes: principio de la integración; principio del aprendizaje desarrollador; principio de la actividad consciente; principio de la inducción y de la construcción; principio de la generalización; y, principio de la proyección. Estos principios se corresponden con las pautas teórico-metodológicas que se describen a continuación:

- Planificación del proceso de construcción activa del conocimiento direccionado bajo el objetivo supremo de la educación, -“aprender a aprender"-, por parte del estudiante. 
- Diagnóstico global de las competencias, niveles, logros, contexto, condiciones cognitivas, procedimentales y actitudinales del estudiante.

- Determinación de momentos y de fases principales del proceso: orientación, ejecución, seguimiento de la actividad y de los medios utilizados que propicien el trabajo autónomo, la capacidad investigativa, la capacidad de búsqueda, procesamiento y sistematización de la información.

- Formulación de un sistema de actividades que propicie la exploración del conocimiento; el posicionamiento crítico y reflexivo; que estimule y promueva el desarrollo del pensamiento; que fomente la necesidad de aprender y de entrenarse en cómo hacerlo; que favorezca una adecuada interacción de lo individual con lo colectivo; que permita el desarrollo intelectual; que genere espacios de vinculación del contenido de aprendizaje con la práctica social; etcétera.

Estas pautas metodológicas se diversifican en una serie de procedimientos conforme a la utilización del enfoque seleccionado: holístico-sinérgico-sistémico; expositivo; problemático-crítico; por experimentación; abordaje por proyectos; enfoque tecnológico; etcétera.

Tanto los principios como las consideraciones teórico-metodológicas permitirán la optimización de los procesos pedagógicos con apoyo tecnológico.

\section{A manera de conclusión}

La tecnología es un compuesto heterogéneo, complejo, dinámico en el que todo se requiere y se interelaciona; 
es una unidad dialéctica en la que coexiste activamente el dato, el hecho, el producto con el conocimiento, la teoría, la conceptualización.

Una de las finalidades de las tecnologías es la tendencia a lograr la transformación del entorno humano (natural y social), para adaptarlo de la mejor forma posible a las necesidades y deseos humanos.

El avance científico y tecnológico genera nuevas formas de ser, de pensar y de estar en el mundo.

El ser humano deberá realizar un uso racional de la tecnología que evite la cosificación, instrumentalización o inclusive su propia destrucción, recordando que la tecnología no es un fin en sí mismo, sino que constituye un medio para alcanzar las metas y objetivos propuestos.

Es preciso considerar que la tecnología en sí no es buena ni mala, es su uso lo que determina la calidad del juicio valorativo emitido por el sujeto que juzga.

Los procesos de formación en valores, así como los procesos de concientización acerca del sentido y del significado del uso de la tecnología podrían contribuir tanto para mitigar los efectos negativos como para potenciar y/o fortalecer los efectos positivos que de ella se deducen.

La tecnología siempre será contemporánea a la época histórica en la que surge.

A través del tiempo se demuestra que el ser humano como creador de tecnología ha ido depositando cada vez más la confianza en sus productos con miras a lograr niveles superiores de desarrollo, de progreso, de superación. No obstante este optimismo atribuido al ser humano en el cumplimiento de la tarea conlleva nuevas esperanzas, desafíos, obstáculos y problemas para la humanidad.

Un ejemplo claro de este optimismo se encuentra representado por la sociedad moderna como se explica en la siguiente paráfrasis: 
La sociedad moderna aspira al progreso técnico, está sometida a lo que Marcuse y Stanislaw Lem han denominado el "imperativo tecnológico" y sus visiones de futuro, se denominen o no "utopías", siempre quedan en el ámbito de lo realizable, pues la técnica es un instrumento que ha perdido su neutralidad moral y exige una dirección preestablecida (Hernández, 2002: 134); por su parte, Spengler fascinado por el poder que emana de la técnica y por el espíritu fáustico, se entrega a ella sin reservas en aras de un "amor fati” libre de prejuicios, lo cual evidencia la confianza ciega en el poder de la técnica. En las utopías actuales, la técnica ya no se puede entender como la consecuencia de una carencia estructural antropológica, más bien la aceleración en el ámbito de la técnica se debe a una novedosa cualidad de la conciencia que aspira a la creación de una nueva humanidad que se asegure el control de la naturaleza y del futuro (cfr. ibíd.: 134).

Una vez que el hombre ha perdido la confianza en el orden cósmico, empieza una nueva obsesión, esta vez por la superación continua y por expandir su poder en todas las direcciones para cubrir los diferentes vacíos generados por el proceso histórico, este proceso se muestra de manera cíclica y de modo indefinido, esto es que, mientras un momento es superado por uno nuevo, el anterior no se suprime sino que es asimilado, re-direccionado y proyectado.

Entonces, la dinámica de la tecnología oscila entre la inicial neutralidad de la técnica y la posterior superioridad o incluso el dominio a la racionalidad, a la inteligencia humana, una especie de sometimiento que obliga a que el ser humano se adapte temporalmente a los nuevos requerimientos y exigencias tecnológicas de la época que le toca vivir.

En fin, nuevas prácticas, sujetos, propuestas y escenarios seguirán surgiendo y continuarán produciendo 
nuevos, variados, múltiples conceptos y otras tecnologías para satisfacer las nuevas necesidades y para responder a los nuevos requerimientos del contexto.

\section{Notas}

1 El positivismo de Comte (siglo XIX) relacionó ciencia y técnica hasta tal punto que la primera se justificaba por la segunda: "Saber para prever y prever para proveer", tal fue el ideal del saber positivista (Cfr. Fullat, 2000: 164).

2 Desde el punto de vista de los productores de bienes y de los prestadores de servicios, las tecnologías son el medio indispensable para obtener réditos económicos. Desde el punto de vista de los consumidores, las tecnologías permiten obtener mejores bienes y servicios. Desde el punto de vista de los trabajadores, las tecnologías disminuyen los puestos de trabajo al reemplazarlos crecientemente con las máquinas.

3 El ludismo o luddismo, es la ideología que atribuye a los dispositivos tecnológicos ser la causa de muchos males de la sociedad moderna. El término fue ideado por Ned Ludd, un personaje destructor de máquinas en la Inglaterra de la revolución industrial (Cfr. Ibid.,: 4)

4 Los estudiosos, suelen distinguir entre tecnologías apropiadas, tecnologías de punta y tecnologías intermedias. Tecnologías de punta, es término publicitario que enfatiza la innovación, son usualmente tecnologías complejas que hacen uso de muchas otras tecnologías más simples. Tecnologías apropiadas, usan saberes propios de la cultura (generalmente artesanales) y materias primas fácilmente obtenibles en el ambiente natural donde se aplican. Tecnologías intermedias es un término acuñado para designar a las tecnologías que comparten características de las apropiadas y de las industriales (Cfr. Sohn, 2011: 2)

5 Entre 1760 y 1800 , algunos pensadores se dieron cuenta de que algo cualitativamente diferente estaba ocurriendo, y que transformaría para siempre el destino de la humanidad. Juan Jacques Rousseau fue uno de estos exponentes sociales. Propuso su Contrato Social, una contribución para la época emergente (Cfr. De Souza Silva, 2001: 2)

6 Con la Revolución Industrial, los bienes y servicios pasaron a ser "producidos" por máquinas, en las fábricas creadas por el sistema de técnicas del industrialismo emergente. Esto representó, el fin de 
la economía basada en el trabajo de los artesanos, el fin social y económico de la relación entre maestros y aprendices. La economía se basa en tres factores: tierra, capital y trabajo. La idea de progreso se introdujo con la premisa de que el crecimiento material era ilimitado y que beneficiaría a toda la humanidad. (Cfr. Ibíd. 2)

7 Durante la revolución industrial, el poder fue transferido a manos de los que poseían el capital industrial, porque éstos pasaron a poseer las fábricas y las máquinas del denominado industrialismo emergente. La dinámica de la situación del poder se encuentra determinada por los factores fuerza, dinero y conocimiento. A partir de esta revolución, la fuerza fue reemplazada por el liderazgo del dinero. (Cfr. Ibid.: 3)

8 La revolución industrial generó impactos radicales en todos los niveles de la existencia. En el caso de la familia, toda su existencia pasó a ser planificada en torno al tiempo mecánico establecido por los relojes de las fábricas; se visualiza la separación de los padres respecto de sus hijos; la separación de los esposos; van proliferando nuevas manifestaciones de vida que tratan de responder al modelo mecanicista que se va configurando (Cfr. Ibíd. 17).

9 Con la revolución industrial, las relaciones sociales (antes de naturaleza orgánica), fueron superadas por relaciones de naturaleza mecánica. El nuevo sistema de ideas promovía los valores requeridos por el industrialismo mecánico: individualismo, eficiencia, productividad, comando, control, cuantificación, disciplina, puntualidad, etc. Estaba en marcha la consolidación de la cultura de la realidad mecánica, donde la metáfora de la máquina servía para todo: para interpretar el mundo y para comprender la vida cotidiana, para actuar sobre la realidad general y para decidir sobre las rutinas domésticas, para inspirar a la educación de las masas y para moldear la práctica científica. Entre los trastornos generados por la revolución industrial estaban: mucha turbulencia, inestabilidad, incertidumbre, desorientación, discontinuidad, inseguridad, fragmentación, perplejidad, etc. (Cfr. Ibíd. 2004: 26)

10 Las poblaciones que habitan en estos ámbitos culturales están a salvo de influencias exteriores y conservan todavía las formas más antiguas de actividad económica: la caza, la recolección de alimentos silvestres, la vida nómada, etc. Sus formas de vida son prácticamente las mismas que hace 1000 o 2000 años. Las prescripciones culturales en el seno de esas culturas son extremadamente compulsivas y no asimilan cambio cultural alguno. Su capacidad para asimilar o tolerar la novedad es prácticamente nula. (Burcet, 2011:34 ) 
11 Estas culturas son muy rígidas frente al cambio y a la novedad, pero durante los últimos 50 años han recibido ciertas influencias superficiales procedentes de otras culturas. En líneas generales, se trata de comunidades agrícolas que son todavía abiertamente preindustriales pero que han recibido y acogido algunas influencias de otras regiones económicamente más prósperas. Su capacidad para asimilar o tolerar la novedad es muy baja. (Ibíd. 25).

12 Estas culturas están más abiertas a la novedad y exhiben una cierta capacidad para llevar a cabo algunos cambios importantes. Sin embargo, mantienen axiomas y postulados considerados muy esenciales que evolucionan todavía con extremada lentitud. Corresponden a las sociedades en proceso incipiente de industrialización y urbanización o las sociedades relativamente industrializadas de evolución más lenta. Su capacidad para asimilar o tolerar la novedad es baja (Ibíd. 27).

13 Estas culturas corresponden a las regiones que se hallan en proceso rápido de desarrollo económico. Están más capacitadas para acoger la novedad aunque persisten todavía con fuerza numerosas inercias culturales. En estas regiones la tensión entre la tradición y la modernidad es particularmente intensa. Actualmente exhiben tasas de crecimiento económico altas y un shock cultural importante derivado de la velocidad con que hacen su proceso de modernización. Su capacidad para asimilar o tolerar la novedad es media con altibajos (Ibíd. 28)

14 Estas culturas, han sido capaces de llevar a cabo cambios rápidos e importantes. Las sociedades que han evolucionado bajo su influjo, han logrado alcanzar plenamente el estadio postindustrial. Sin embargo, en su evolución más reciente dan muestras cada vez más palpables de un cierto estancamiento que les impide abandonar las coordenadas del estado del bienestar postindustrial y parecen incapaces de abandonarlo (Ibíd. 29)

15 Estas culturas, hasta hace muy poco eran indistinguibles con respecto a las anteriores. Estas culturas serían las que van a lograr ir más allá del estadio postindustrial: asimilando mejor la globalización; adaptándose rápidamente a las condiciones creadas por la deslocalización; abandonando las coordenadas mentales del estado del bienestar (proteccionismo paternalista del estado, intentos de reducir la velocidad de los cambios rápidos, etc.); logrando una asimilación más fluida y eficiente de las nuevas situaciones surgidas de la explosión de la comunicación (Ibíd. 32).

16 Es necesario recordar que el único ser educando es el ser humano, solamente la educandidad es prerrogativa humana. La educabili- 
dad, lo educable pertenece también a otros seres vivos. (Cfr. Fullat, 2000: p. 30).

17 Asumiendo el estatus de paradigma social (Capra 1982, citado por De Souza Silva, 2004: 32), una visión de mundo es el elemento cultural de referencia más poderoso de que dispone un grupo social, una comunidad o una sociedad, para (re)interpretar su pasado, comprender su presente y construir su futuro.

18 La tecnociencia (la fusión de la ciencia moderna con la tecnología moderna); es un factor de transformación de ciertos insumos en información y tecnología, para aumentar la eficiencia de ciertos procesos productivos (Cfr. De Souza Silva, 2004: 25- 27).

\section{Referencias bibliográficas}

BURCET LLAMPAYAS, Josep

2010 Desarrollo del Paradigma de las Interacciones. Icaria Editorial, Barcelona, España.

La mirada científica. Icaria Editorial, Barcelona, España, 2011.

Sostenibilidad y Explosión de las Comunicaciones, Icaria Editorial, Barcelona, España, 2006.

Impacto de las Nuevas Tecnologías en las organizaciones, Aguilar, Madrid, Círculo de Lectores, Barcelona, 1987.

La aldea global. Gedisa, Barcelona, 1991.

Guerra y paz en la aldea global, Martínez Roca, Barcelona, 1971.

Comprender los medios de comunicación: las extensiones del ser humano, Paidós, Barcelona, 1995.

CASTELLS, Manuel

1971 Problemas de investigación en sociología urbana. Editorial Siglo XXI. Madrid, España.

La cuestión urbana. Siglo Veintiuno de España Editores, S.A. Primera edición en español, 1974.

Nuevas perspectivas críticas en educación. Barcelona: Paidós, 1994.

La ciudad informacional. Tecnologías de la Información, reestructuración económica y el proceso urbano-regional. Madrid: Alianza Editorial, 1995.

Local y global. La gestión de las ciudades en la era de la información. Madrid: Taurus. (en colaboración con J. Borja), 1988. 
La Era de la Información. Vol. II: El poder de la identidad. México, Distrito Federal: Siglo XXI Editores, 2001.

La Era de la Información. Vol. III: Fin de Milenio. México, Distrito Federal:Siglo XXI Editores, 2001.

La Galaxia Internet. Reflexiones sobre Internet, empresa y sociedad. Madrid: Areté, 2001.

La Era de la Información. Vol. I: La Sociedad Red. México, Distrito Federal: Siglo XXI Editores, 2002.

El estado del bienestar y la sociedad de la información. El modelo finlandés. Madrid: Alianza Editorial, 2002. La Sociedad Red. Alianza Editorial. Madrid, 2006.

DE SOUZA SILVA, José

2004 "Un epitafio para la "idea de desarrollo" por organizar la hipocresía y legitimar la injusticia”. Concurso de Ensayo "Pensar a Contracorriente". Instituto Cubano del Libro, febrero - mayo. El Cambio de Época, el Modo Emergente de Generación de Conocimiento y los Papeles Cambiantes de la Investigación y Extensión en la Academia del Siglo XXI. Trabajo invitado para la "I Conferencia Interamericana de Educación superior y Rural”, organizada por el IICA, realizada en Panamá, 16-19 de noviembre, 1999.

DE SOUZA SILVA, José, CHEAZ, J y CALDERÓN, J.

2001 "La Cuestión Institucional: de la vulnerabilidad a la sostenibilidad institucional en el contexto del cambio de época". Serie Innovación para la Sostenibilidad Institucional. San José, Costa Rica: Proyecto ISNAR "Nuevo Paradigma".

GARCIA CARRASCO, Joaquín y GARCÍA PEÑALVO, F. J.

2009 Marco de referencia pedagógico en el contexto informacional.

GARCIA CARRASCO, Joaquín y GARCÍA DEL DUJO, Angel

1999 Teoría de la Educación II. Procesos primarios de formación del pensamiento y la acción.

Teoría de la Educación: Educación y acción pedagógica. Ediciones Universidad de Salamanca. Gráficas Varona. Salamanca-España, 1996.

LECHNER, Norbert

1997 El malestar con la política y la reconstrucción de los mapas políticos. En: Winocur, R. (Compilación). Culturas políticas a fin de siglo. México. Juan Pablo Editor, S.A. pp 15 - 35. 
MCLUHAN, Marshall y POWERS, Bruce

1994 "La aldea global. Transformaciones en la vida y los medios de comunicación mundiales en el siglo XXI". Edit. PlanetaAgostini, Barcelona (España).

MCLUHAN, Marshall

1996 “Comprender los medios de comunicación”. Editorial Paidós.

MCLUHAN, Marshall y QUENTIN Fiore

1997 El medio es el mensaje. Editorial Paidós.

MOLINA, María Lorena

2004 "La Cuestión Social y la Formación Profesional en Trabajo Social en el Contexto de las Nuevas Relaciones de Poder y la Diversidad Latinoamericana”. Espacio Editorial, Buenos Aires, Argentina.

RODRÍGUEZ, Ángel

1988 Socialización política. Capítulo 5.V En Psicología política. Madrid, Ediciones Pirámide, S.A.

SOLIVÉREZ, Carlos Eduardo

2003 "Educación Tecnológica para comprender el fenómeno tecnológico". Instituto Nacional de Educación Técnica, Buenos Aires Argentina.

Tecnologías, sociedad y naturaleza: los por qué, para qué y cómo de la Educación Tecnológica; San Carlos de Bariloche, Río Negro, Argentina, 2011.

Ciencia, técnica y sociedad, Facultad Latinoamericana de Ciencias Sociales, Buenos Aires (Argentina), 1992.

Las tecnologías en Argentina: breve historia social. Edit. Capital Intelectual; Buenos Aires, 2006.

VERE GORDON, Childe

1997 Los orígenes de la civilización”. Editorial Paidos. Madrid.

La historia de las herramientas. Alianza Editorial. Madrid. España, 2009.

\section{Documentos Electrónicos:}

ABAUNZA GUTIÉRREZ, Humberto

2009 “La política, la socialización y la ciudadanía juvenil”, en: http:// humbertoabaunza.blogspot.com/2009_03_01_archive.html

DE SOUZA SILVA, José

2004 "La Educación Latinoamericana en el Siglo XXI. Escenarios hacia las pedagogías de la alienación, domesticación y transformación”. Red "Nuevo Paradigma” para la Innovación Institucional en América Latina. Instituto Internacional de 
Investigación sobre Políticas Alimentarias (IFPRI). San José, Costa Rica, págs.. 1-46, en: http://www.apse.or.cr/webapse/ pedago/enint/souza04.pdf

“¿Una época de cambios o un cambio de época? Elementos de referencia para interpretar las contradicciones del momento actual" . Publicación del Instituto Científico de Culturas Indígenas. Año 3, No. 25, abril. Boletín ICCI "RIMAY”, en: http://icci.nativeweb.org/boletin/25/souza.html, 2001.

LAZO, Miguel

2006 Curso Cambio Global de la sociedad, en: http://www. mailxmail.com/curso-cambio-global-sociedad

SOHN, Alan

2011 "Tecnología”, Wikipedia, en: http://es.wikipedia.org/wiki/ Tecnolog\%C3\%ADa. 